\title{
(t)
}

\section{GÊNERO, IDENTIDADE E POLÍTICA: E AGORA, AONDE VAMOS?}

GENDER, IDENTITY AND POLITICS: WHERE DO WE GO NOW?

\section{Carla Lima Almeida' Ana Lole ${ }^{2}$}

\section{RESUMO}

Este artigo discute os desafios dos estudos de gênero na atualidade focalizando o âmbito das pesquisas e das estratégias políticas e profissionais no que tange à construção de práticas emancipatórias. Examina os dilemas que envolvem a relação entre igualdade e diferença na perspectiva da política feminista e da formulação das políticas de proteção social em geral. Para tanto, toma como inspiração o filme $E$ agora, aonde vamos? (França-Líbano-Egito-Itália, 2011) e recupera as recentes problematizações em torno da categoria gênero e suas articulações com a produção de identidades dos sujeitos. Discute as respostas a essas tensões formuladas por diferentes perspectivas, buscando fortalecer a pertinência desse debate no cenário contemporâneo.

Palavras-chave: Gênero. Identidade. Diferença. Política.

\section{ABSTRACT}

This article discusses the challenges of gender studies in the present, by focusing the researches and political and professional strategies in relation to the building of emancipating practices. The dilemmas that involve equality and difference relationship are examined in feminist

1 Assistente Social, Professora Adjunta da Faculdade de Serviço Social da UERJ, Departamento de Fundamentos Teórico-Práticos do Serviço Social, mestrado em Sociologia e Antropologia pela UFRJ, doutorado em Ciências Sociais pela UNICAMP, pós-doutorado no Núcleo de Estudos de Gênero - PAGU/UNICAMP. E-mail: carlalima.almeida@hotmail.com.

2 Doutoranda em Serviço Social pela PUC-Rio. E-mail: analole@gmail.com. 


\section{temporalis}

policy and in social protection policies formulation perspective. For both, it takes the movie "Where Do We Go Now?" (France-LebanonEgypt-Italy, 2011) as inspiration and rescues recent formulations around gender category and its articulations with subject identities production. It discusses the responses to these tensions formulated by different perspectives, searching to fortify the relevance of this debate in contemporary setting.

Keywords: Gender. Identity. Difference. Politics.

Submetido em 25/03/2014

Aceito em 28/10/2014

\section{INTRODUÇÃO}

Neste artigo, refletimos sobre alguns desafios que envolvem as pesquisas que trabalham com o gênero, os quais se relacionam à trajetória dos estudos na área, bem como aos debates contemporâneos acerca do conceito e dos rumos políticos que a envolvem. A primeira lição que aprendemos nos estudos de gênero é que este é um campo de intensos debates, calorosas discussões e com perspectivas teóricas e filosóficas bastante variadas. Então, aquilo que para um público "externo" parece unitário é, de fato, extremamente diversificado.

Os estudos de gênero trazem para a arena política o debate entre igualdade e diferença, o que, situado no contexto do mundo moderno, nos remete à pluralidade acerca do estatuto das identidades sociais no jogo político. Esse cenário torna mais aguda a necessidade de refletir sobre os projetos societários e sua articulação com os valores da igualdade e da diferença. Se as individualidades são autorreferenciadas, elas podem ignorar o conjunto da sociedade. Resgatar os valores da diferença não pode nos levar ao retorno do naturalismo, e sim nos remeter à perspectiva de emancipação.

Scott (2005, p. 12) nos alerta para o fato de "que os debates atuais sobre igualdade e diferença, direitos individuais e identidades de grupo tomam forma polarizada". Partindo desse pressuposto, as contradições da construção do gênero são também as contradições na concepção histórica de igualdade. Os recentes debates teóricos e políticos sobre as estratégias de luta contra a desigualdade contribuíram para apresentar os estorvos da 
oposição identidade-diferença, na qual ficou preso o princípio de igualdade. No Brasil, o processo implementado de garantia de direitos revelou debilidades, localizadas no modelo privatista em que vem se sustentando, apesar da ampla presença da sociedade civil organizada e de inúmeros mecanismos de controle social. O princípio da universalidade se vê ameaçado por uma noção de cidadania diferenciada que se espraia em direção a minorias de todos os tipos, que justifica qualidades diferentes de acessos a serviços e a direitos. A diferença é vista com desconfiança, acusada de provocar um enfraquecimento e fragmentação dos modos de fazer política e de seus resultados.

Assim, ainda que recorrente na literatura do gênero, o estudo desse tema continua pertinente, tendo em vista a necessidade de formular respostas as dicotomias e oposições que dificultam a construção da política numa perspectiva emancipatória. A persistência da desigualdade, apesar das políticas sociais antidiscriminatórias e de inclusão, e sua capacidade de se revestir de formas novas e inéditas, orientam a reflexão feminista ao reexame crítico das categorias e das ferramentas conceituais com as quais compreendemos a desigualdade dos sexos (VARIKAS, 2009a).

A ideia de utilizar esse tipo de linguagem (filmes) em estudos acadêmicos tem sido experimentada em várias áreas, tais como história, antropologia, educação, além de, naturalmente, a comunicação. Todavia, no Serviço Social estudos sobre mídia e cinema não são recorrentes, o que torna relevante explorar esse viés de investigação não apenas por seu ineditismo como também pela diversificação do modo de observar processos sociais, políticos e culturais que atravessam as relações entre Estado e sociedade.

Ao tratarem o cinema como documento, os estudiosos inscrevem-no na perspectiva de que documento é monumento. Isto é, "resulta do esforço das sociedades históricas para impor ao futuro - voluntária ou involuntariamente - determinada imagem de si próprias". (ESTEVES, 2007, p. 73). Desse modo, o cinema pode ser percebido como uma forma de exibição do social ou do poder político através da imagem, do rito, de certa "estilização da vida" (ESTEVES, 2007, p. 17). 


\section{temporalis}

Neste estudo, seguimos com o pensamento de Aumont ( $p$. 98-99 apud ESTEVES, 2007, p. 59), ao dizer que

em um filme $[. .$.$] a sociedade não é propriamente$ mostrada, mas sim encenada: Em outras palavras, o filme opera escolhas, organiza elementos entre si, decupa no real e no imaginário, constrói um mundo possível que mantém relações complexas com o mundo real.

Assim, a pesquisa do cinema e o cinema como pesquisa alargam nossas possibilidades de compreensão das relações sociais e talvez se tornem tão atrativos pelas razões que Xavier (2008, p. 17, grifos nossos) tão bem localiza:

O modernismo nos legou este imperativo de desautomatização da percepção e de ampliação de repertório como tarefa da arte, recuperação de uma sensibilidade amortecida pelo investimento prático em que o cotidiano se faz o lugar do hábito, da percepção que está instrumentada por uma interação com o mundo marcada pelo cumprimento de certas finalidades, das mesmas finalidades a cada novo dia.

\section{AONDE VAMOS?}

Não poderia ser melhor a inspiração vinda do filme lançado em 2011, da diretora e atriz Nadine Labaki, intitulado E agora, aonde vamos?, uma coprodução França, Líbano, Egito, Itália.

Num vilarejo libanês, cristãos e muçulmanos convivem pacificamente, isolados do resto do mundo, graças ao colapso providencial de uma ponte. Mas de vez em quando os ecos da guerra, que recomeçou no país, chegam a eles por meio de uma televisão improvisada, e as mulheres se reúnem em segredo para encontrar um modo de dissuadir os homens de quebrarem essa tênue possibilidade de diálogo que se instaura entre os dois grupos. Nessa pequena comunidade, vivem juntos cristãos e muçulmanos que se conhecem desde criança e gerenciam pacificamente seus negócios na sombra de uma mesquita e de uma igreja. O pequeno cemitério do vilarejo, dividido inexoravelmente em dois setores, está repleto de sepulturas de maridos, filhos e pais que as mulheres de ambos os lados já estão cansadas de visitar para renovar as flores e limpar as fotos de lembrança. Juntamente com outras 
mulheres do vilarejo, inventam de tudo para distrair os seus homens e evitar que se matem uns aos outros pelo ódio religioso, pela vingança ou simplesmente para defender seu orgulho.

Nessa fábula contemporânea, encontramos elementos férteis que nos ajudam a pensar nossa experiência como sujeitos individuais e coletivos, aspectos que domina(ra)m os dilemas e tensões no campo dos estudos de mulher e de gênero através dos tempos.

A história das mulheres e de como suas experiências constituíram-se em novas narrativas do mundo, ensejando práticas políticas, institucionais, pessoais e de outros idiomas, é recheada de cenas como as do filme. Há negociações, manobras arriscadas (como as que aparecem quando manipulam os artifícios femininos para barganharem a paz dos homens), gestão do cotidiano e de suas dores, articulando o biográfico e o histórico; tal como na clássica formulação tão nossa conhecida: "o pessoal é político".

Os estudos de gênero em distintos campos disciplinares não cessam de mostrar registros de como as mulheres teciam no cotidiano e nas sombras, seja no espaço público, seja no privado, formas de luta na garantia de seus interesses pessoais e coletivos. Uma importante contribuição desses estudos tem sido revelar a falácia da separação das esferas pública e privada, bem como as lacunas deixadas por um tipo de conhecimento que rejeita tal articulação. Costa (2002, p. 302) salientou no âmbito dos estudos sobre proteção social que "a teoria das esferas separadas esconde as conexões entre a história das mulheres e a política, e acoberta os significados políticos das relações de gênero e das práticas protecionistas".

Além de alijar as mulheres da política, outro efeito é despolitizar o conjunto das ações, expectativas e interesses que movem as mulheres na vida social. Se por um lado as mulheres, enquanto grupo coletivo, ensejam o reconhecimento social e político, por outro, é pertinente indagar a própria constituição do termo mulher como identidade do sujeito. Nesse ponto, nossa reflexão encaminha-se diretamente para o cenário contemporâneo, no qual as identidades estão abertas à construção, pensamento que provoca uma fissura e favorece a problematização da categoria gênero. 


\section{temporalis}

Butler (2003, p. 29), ao discutir o "sujeito" do feminismo, pondera que o gênero se relaciona com outras modalidades discursivas raciais, classistas, étnicas, religiosas, sexuais, o que nem sempre tornou a sua constituição coerente e consistente. Assim, a política fundamentada no aspecto identitário porta "um termo problemático, um ponto de contestação, uma causa de ansiedade".

Notadamente nos colocamos diante de uma reflexão que problematiza a um só tempo a constituição dos sujeitos e as estratégias coletivas de luta política. Trata-se de um debate que provoca reações, receios de que o "problema do sujeito" redunde na fragmentação e na fuga da perspectiva universalista que as políticas emancipatórias buscam alcançar.

\section{O PROBLEMA DA IDENTIDADE}

Certamente, para enfrentar os diferentes etnocentrismos que nos povoam é necessário um trabalho de ruptura. Uma delas diz respeito à metáfora da "sororidade", sobre a qual Costa (2009) pôs-se a analisar, mediante as indicações de Kristeva, a partir das experiências das mulheres no Rio de Janeiro promovidas no âmbito do que ficou conhecido como feminismo para a saúde.

Sob a simbologia da "sororidade", conceberam-se conceitos sobre processos identitários "naturalmente" vividos pelas mulheres em suas relações entre si, moldados por sentimentos e sensibilidades inclusive das mulheres feministas de diferentes tempos forjados, sobretudo, na experiência da maternidade vista como "igual" para todas (COSTA, 2009, p. 21).

O que está posto aqui é a ideia de um "pluralismo de mulheres", crítica acentuada pelas feministas francesas, que suspeitaram da "sororidade" como fundamento intrínseco do gênero - problematização que foi, entretanto, pouco acionada nos debates no Brasil dos anos de 1980, como salienta Costa (2009). Nesse período, ao contrário, o ideal de "sororidade" é patente nos trabalhos e nas bases que fundamentam as principais iniciativas de políticas públicas voltadas para as mulheres na saúde, mas, não 
somente nesse campo, tendo em vista que se espraiava como elo de articulação de um sujeito individual, biográfico e coletivo, político: mulher.

Em pesquisa realizada entre final da década de 1970 e meados de 1980, Kofes (2001) produziu um trabalho dissonante para o período em termos da analítica das mulheres. Mulher, Mulheres, defendida como tese de doutorado em 1991 e publicada dez anos depois, expunha uma etnografia da relação social entre patroas e empregadas domésticas. Além das inúmeras contribuições conceituais formuladas pela autora, tomando nota de revisões teóricas em torno do "doméstico", dois aspectos fundamentais emergem desse trabalho.

Em resenha publicada na Revista Brasileira de Ciências Sociais, Simões (2002) situa uma importante contribuição do estudo, que, dentre outros aspectos, dá visibilidade aos debates internos nos estudos feministas.

$\mathrm{Na}$ construção do objeto e da abordagem, Kofes parte da crítica às discussões feministas de inspiração marxista na década de 1970, que buscavam explicar o trabalho doméstico assalariado a partir das noções de modo de produção doméstico, trabalho produtivo e improdutivo, e exército industrial de reserva. Embora tais conceituações sublinhassem o papel dos serviços domésticos na reprodução social mais ampla, elas permaneciam presas a distinções dualistas entre setores "centrais" e "periféricos", "estratégicos" e "intersticiais", relegando a família e o trabalho doméstico ao segundo termo de cada uma dessas polaridades e dissolvendo no personalismo e na afetividade a complexidade das relações sociais no interior da casa (SIMÕES, 2002, p. 150).

Diante desse quadro, o trabalho de Kofes expõe alternativas interpretativas que entrelaçam os produtos da desigualdade à estrutura do parentesco e da família nas sociedades modernas. Desse modo, como afirma Simões (2002, p. 150), "relações de classe e trabalho são também sobrecodificadas pelas relações familiares e marcadas pelas distinções de gênero". Esse aspecto, entretanto, constitui até hoje um dos elementos desafiadores nos estudos de gênero. 


\section{temporalis}

O segundo aspecto a ressaltar dessa obra vem corroborar aquilo que outras autoras (COSTA, 2009; DEBERT, 2005) sinalizaram. Ao lançar o foco do estudo sobre a relação entre as mulheres, Kofes diz que pensar que "as experiências femininas se singularizam exclusiva e necessariamente em contraposição a um suposto polo fixo contrário, o 'masculino'" (SIMÕES, 2002, p. 151), é invisibilizar as diferentes formas e situações nas quais o agenciamento das identidades se processa.

Kofes (2001) está preocupada em mostrar que do encontro entre mulheres não nasce "naturalmente" nem necessariamente uma identidade comum. Portanto, gênero tem de ser analisado em sua pluralidade e diversidade, não se constituindo desse modo numa categoria natural referente a uma identidade autocontida e estável, edificada a partir da essencialização do corpo.

Esses argumentos põem em dúvida o edifício da construção dos sujeitos coletivos baseado em uma identidade não problemática, coesa, imutável e solidária. E mais ainda, essa reflexão nos dirige ao segundo ponto desta discussão, inspirada no filme de Labaki: estamos diante de uma fantasia das identidades?

Bauman (2011, p. 20) propõe que as identidades hoje somente existem em processo de contínua renegociação. Diz o pensador:

A formação da identidade, ou, mais corretamente, sua reformação, tornou-se tarefa vitalícia, jamais completada. Em nenhum momento da vida a identidade é "final". Sempre estará pendente uma tarefa de reajuste, uma vez que nem as condições de vida nem os conjuntos de oportunidades e ameaças cessam de mudar.

No âmbito do gênero, esse debate fertilizou um conjunto de reflexões que, ao propor "a noção de sujeito como lugar de subjetividades múltiplas e potencialmente contraditórias" (MOORE, 2000, p. 23), assumiu que a tarefa fundamental dos estudos de gênero constitui identificar os processos, as situações, os contextos onde as diferenças são formuladas. Mais do que pensar o gênero como descrição de pessoas, sujeitos empíricos, deve-se pensá-lo como processos mediante os quais as identidades 
são negociadas e que fundamentam as práticas institucionais e sociais, ou seja, o gênero constitui-se como um idioma para se falar de processos e relações, mais do que o que um sujeito é (STRATHERN, 2006).

Evidencia-se no debate contemporâneo da área um esforço de pensar "gênero de maneira não identitária" (PISCITELLI, 2005). O problema seria depreender daí um modo de fazer política capaz de responder aos dilemas da desigualdade tal como se expressam no âmbito das hierarquias de gênero.

Fugindo dos esquemas que acentuam gênero como definição do que alguém é, resta lidar com a pluralidade que atravessa as experiências dos sujeitos, sendo a tônica no debate atual a ideia de interseccionalidade, em que diferentes marcadores sociais se entrecruzam e potencializam a produção de distinções, diferenças, identidades. Cabe destacar que isso requer a produção de um conhecimento situado e contextualizado. É preciso ainda esclarecer a noção de "experiência", a qual reflete não uma realidade objetiva prévia, mas, como retrata Varikas (1994, p. 82) acerca dos estudos da história,

\begin{abstract}
os numerosos escritos que essas mulheres deixaram, tratando não somente do que era ou deveria ser uma mulher, ou uma operária, ou uma cidadã, mas também das maneiras como elas mesmas viveram e interpretaram sua existência de mulher, de operária ou de não cidadã.
\end{abstract}

A resolução proposta pelas mulheres do filme - E agora, aonde vamos? - joga exatamente com essa consciência de que as identidades podem ser manipuladas, acionadas, invertidas sendo, portanto, uma ficção em mãos carregadas de intencionalidades. A eficácia dessa operação em quem assiste - nos parece - é expor o ridículo e o cômico, senão o trágico, da crença de que identidades étnicas, religiosas, de gênero, raciais e outras tantas possam efetivamente falar do que um sujeito é e agrupar práticas de segregação, poder, exclusão. 


\section{temporalis}

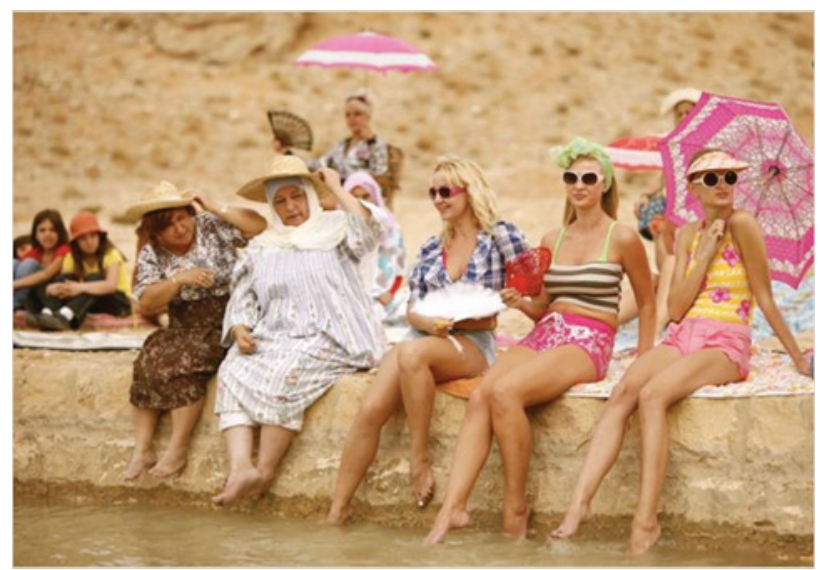

Cena do filme E agora, aonde vamos? (LABAKI, 2011).

Mas, resta ainda indagar: quais são as consequências políticas desse jogo e dessa fragmentação?

\section{MULHERES \& FEMINISMOS: UMA PISTA PARA TRILHAR}

$\mathrm{Na}$ perspectiva de que estamos em um campo altamente diversificado, Debert (2005) apresenta três aspectos que poderiam dar um substrato comum aos diferentes feminismos.

Em primeiro lugar, encontramos um elo "(n)a defesa da igualdade ou (n)a oposição às formas de hierarquia entre os sexos [...] seja na defesa do direito à igualdade ou do direito à diferença". O segundo aspecto é "o reconhecimento que a condição da mulher é socialmente construída e, portanto, possível de ser contestada e redefinida"; e, por último, "a identificação das mulheres como grupo social oprimido e a luta pela libertação da condição de opressão" (DEBERT, 2005, p. 54-55).

Entretanto, nenhum desses três eixos dá ao feminismo um caráter coeso. É preciso mencionar as profundas rupturas trazidas à tona pela experiência das mulheres negras e lésbicas que colocam em xeque os limites e os pressupostos em que se funda a construção de "um coletivo de mulheres". Esse aspecto, associado à teoria feminista da desconstrução, abalou nossas certezas em torno do sujeito "mulheres", ou melhor, como afirma Debert (2005, p. 66), "alimentou a suspensão da categoria mulher 
iniciada pela exigência de diferenciação política dos movimentos sociais".

Em seu artigo “Onda, rizoma e 'sororidade' como metáforas: representações de mulheres e dos feminismos (Paris, Rio de Janeiro: anos 70/80 do século XX)" Costa (2009, p. 12) aponta as questões a problematizar nas produções sobre mulheres e feminismos, sugerindo a necessidade de "voltar o foco das investigações para indícios e resistência e contrarresistência femininas". Endossa, assim, a necessidade de refinar o olhar para as experiências tornadas invisíveis que atuam na construção da história.

Grande parte dessa "invisibilidade" ocorre em função dos instrumentos e categorias de análise que utilizamos, em geral bastante enviesadas. Esse, aliás, tem sido um dos dilemas que acompanham o casamento feminismo e estudos de gênero/ mulheres ao longo do tempo, visto que o pressuposto da opressão feminina, da dominação masculina ou do patriarcado carregou os estudos do período de um conjunto de ideias que, se não paralisavam, tornavam inoperantes as pesquisas realizadas, posto que não importassem as equações, todas chegavam aos mesmos resultados.

Temos o dilema entre produzir pesquisas sofisticadas, que apostam na contextualização e produção de conhecimentos situados, e o desconforto que estas geram ao desmontar, ao menos em parte, o edifício sólido do debate feminista. Como desenrolar a luta política em face da "experiência das mulheres"?

Butler buscará equacionar esse problema assumindo a crítica ao sujeito universal, ao invés de se desvencilhar dela, como parte da tarefa política.

Se a noção estável de gênero dá mostras de não mais servir como premissa básica da política feminista, talvez um novo tipo de política feminista seja agora desejável para contestar as próprias reificações do gênero e da identidade - isto é, uma política feminista que tome a construção variável da identidade como um pré-requisito metodológico e normativo, senão como um objetivo político (BUTLER, 2003, p. 23). 


\section{temporalis}

Todavia, o dilema da construção política de sociedades mais igualitárias e emancipatórias expõe o que Scott chamou de "paradoxo da igualdade", cujas tensões sugerem tratamento igual para os iguais, e diferenciado se a situação das pessoas envolvidas for essencialmente distinta. A autora defende que as melhores soluções políticas na atualidade reconhecem os perigos de insistir em uma solução final e totalizante (ou grupos ou indivíduos, ou igualdade ou diferença). Scott (2005, p. 14) afirma que "igualdade e diferença não são opostos, mas conceitos interdependentes que estão necessariamente em tensão". Nesse sentido, torna-se possível pensar em uma cidadania universal e não diferenciada.

É importante observar que a noção de cidadania, historicamente, se desenvolveu como sinônimo de universalidade. A noção de "cidadania para todos", entretanto, diante das desigualdades colocadas pela sociedade de classes, vem traduzindo dilemas de longa duração na construção de um sistema universal de proteção social. Dessa forma, verifica-se que programas com base nas diferenças tendem a ampliar desigualdades ou, até mesmo, a discriminação por classes, gêneros, raças/etnias e gerações. A noção de diferença faz com que grupos distintos, em suas lutas específicas, acabem se distanciando do conceito de cidadania universal.

Nessa lógica, a articulação entre totalidade e particularismo-universalismo resolveria essa tensão ao recuperar a totalidade como síntese das particularidades e não negação destas, como ocorre comumente na apreensão desse conceito de um ângulo mais ortodoxo. O binômio universalismo-particularismo faz parte de uma configuração política moderna, em que, segundo Varikas (2009b, p. 267), em vez de "[...] um processo sempre aberto às particularidades que o compõem, o universal tendeu a se identificar com o mais forte, rejeitando o fraco como particular e até mesmo como particularismo".

Assim, o problema que as políticas contemporâneas parecem expressar pode ser percebido nos seguintes termos:

O paradoxo da diferença, entre os séculos XIX e XX, estará na ideologia das esferas separadas e formulará políticas diferencialistas, "próprias" às mulheres, esmaecendo as de cunho universalista e, portanto, 
igualitário. Nesse mesmo tempo, são muitos os sinais da marcha que sublinha o ideal da equidade em geral e dos gêneros, em especial, essa última, hoje, mais viva que nunca entre nós (COSTA, 2010, p. 215).

\section{CONCLUSÕES}

Estão postos o desafio e a necessidade de operar com esse debate nas pesquisas e nas ações políticas e profissionais. Como o gênero, concebido dessa forma, ajuda a pensar os sujeitos de nossas pesquisas? Como desvela os processos e contextos onde se tecem e dinamizam as diferenças? Desenhar políticas públicas e formular direitos sociais... com qual perspectiva?

No ponto de vista político feminista, desessencializar o conceito "mulher" (e "homem" também) e problematizar concepções como "universalidade da dominação masculina" reacendem as críticas que apontam para o distanciamento entre as reflexões teóricas fundadas nessa perspectiva e o movimento político (PISCITELLI, 2005).

Nessa direção, Debert (2005) acredita que "a diferença possa fazer a diferença política", em vez de enfraquecê-la. Trata-se de pensar a diversidade não como esvaziamento do agenciamento do grupo, do coletivo, mas como outra experiência, nova, a lidar com os desafios contemporâneos.

No âmbito do Serviço Social, esse debate torna-se relevante, considerando-se que a atuação profissional do ponto de vista acadêmico, interventivo e político envolve um conjunto de relações de desigualdades e hierarquias marcadas por classe, gênero, sexualidade, raça/etnia, entre outros aspectos. Desse modo, a análise das diferentes perspectivas que têm orientado o horizonte das lutas por direitos sociais no campo do gênero possibilita uma maior fundamentação de nossas ações.

Nesse sentido, o texto buscou evidenciar os dilemas de uma perspectiva que toma a construção do gênero e das identidades atribuídas socialmente de modo essencializado, natural e autorreferente. Defende uma visão que considera o gênero não como aquilo que um sujeito é, mas como processos sociais, culturais e políticos mediante os quais as identidades são continuamente 


\section{temporalis}

produzidas. Este artigo propôs uma articulação entre identidade e diferença, particularidade e universalidade que fomente as lutas emancipatórias dos sujeitos em distintas situações de opressão no contexto societário atual. Desse modo, as diferenças não significam fragmentação, ao contrário, permitem a construção criativa de engajamentos políticos coletivos mais significativos.

Em E agora aonde vamos? as mulheres dançam, tomam a diferença não como desunião, mas como força ... elas se veem diferentes? Em que medida? Até onde? Diferenças não são abissais...

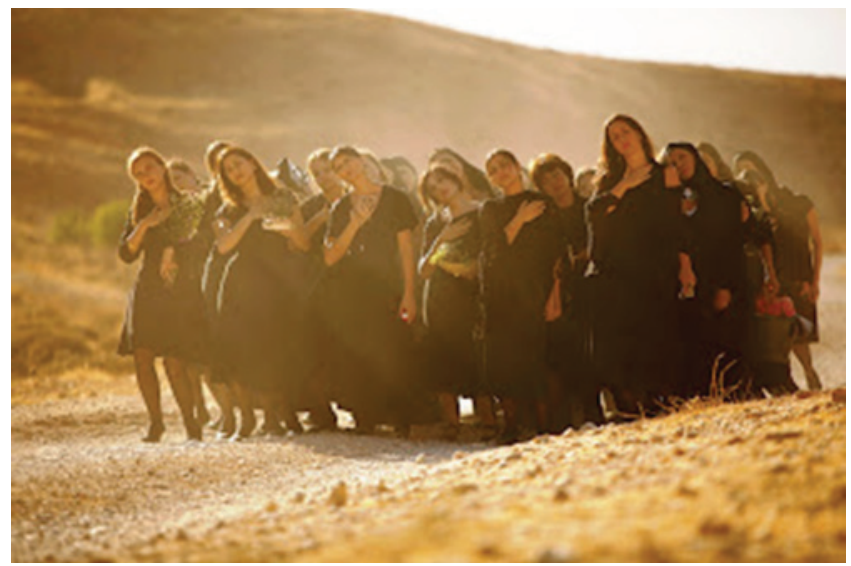

Cena do filme E agora, aonde vamos? (LABAKI, 2011).

\section{REFERÊNCIAS}

BAUMAN, Z. A Ética é possível num mundo de consumidores? Rio de Janeiro: Zahar, 2011.

BUTLER, J. Problemas de Gênero: feminismo e subversão da identidade. Rio de Janeiro: Civilização Brasileira, 2003.

COSTA, S. G. Proteção social, maternidade transferida e lutas pela saúde reprodutiva. Revista Estudos Feministas, Florianópolis, ano 10, p. 301-323, $2^{\circ}$ semestre 2002.

. Onda, rizoma e "sororidade" como metáforas: representações de mulheres e dos feminismos (Paris, Rio de Janeiro: 
anos 70/80 do século XX). Revista Interdisciplinar INTERthesis, Florianópolis, v. 6, n. 2, p. 01-29, jul./dez. 2009.

. O paradoxo da diferença: "verdadeiro, falso e fictício". Estudos Históricos, Rio de Janeiro, v. 23, n. 45, p. 210-218, jan.-jun. 2010.

DEBERT, G. Os estudos de Gênero na UNICAMP. In: MORAES, M. L. (Org.). Gênero nas fronteiras do Sul. Campinas: PAGU/UNICAMP, 2005. p. 66-74.

ESTEVES, Flávia P. "Sob" Sentidos do Político: história, gênero e poder no cinema de Ana Carolina (Mar de Rosas, Das Tripas Coração e Sonho de Valsa, 1977-1986). 2007. Dissertação (Mestrado em História) - Universidade Federal Fluminense, Rio de Janeiro, 2007.

KOFES, S. Mulher, Mulheres: identidade, diferença e desigualdade na relação entre patroas e empregadas. Campinas: Editora da Unicamp, 2001.

MOORE, H. Fantasias de poder e Fantasias de identidade: gênero, raça e violência. Cadernos Pagu, Campinas, v. 14, p. 13-44, 2000.

PISCITELLI, A. As viagens das teorias no embate entre práticas acadêmicas, feminismos globais e ativismos locais. In: MORAES, M. L. (Org.). Gênero nas fronteiras do Sul. Campinas: PAGU/ UNICAMP, 2005. p. 143-163.

SCOTT, J. O enigma da igualdade. Revista Estudos Feministas, Florianópolis, v. 13, n. 1, p. 11-30, 2005.

SIMÕES, J. Mulheres, diferenças e desigualdades. Revista Brasileira de Ciências Sociais, São Paulo, v. 17, n. 49, p. 149-153, jun. 2002.

STRATHERN, M. O gênero da Dádiva: problemas com as mulheres e problemas com a sociedade na Melanésia. Campinas: Editora da Unicamp, 2006. 


\section{temporalis}

VARIKAS, E. Gênero, Experiência e Subjetividade: a propósito do desacordo Tilly-Scott. Cadernos Pagu. Campinas: PAGU/ UNICAMP, v. 3, p. 63-84, 1994.

- Igualdade. In: HIRATA, H. et al. (Org.). Dicionário crítico do feminismo. São Paulo: Unesp, 2009a. p. 116-122.

- Universalismo e particularismo. In: HIRATA, H. et al. (Org.). Dicionário crítico do feminismo. São Paulo: Unesp, $2009 \mathrm{~b}$. p. 266-271.

XAVIER, Ismail. Um Cinema que "Educa” é um Cinema que (nos) Faz Pensar. Revista Educação e Realidade, Porto Alegre, v. 33, n. 1, p.13-20, jan./jun. 2008.

\section{FILME}

E AGORA, AONDE VAMOS?. [Ou Halla La Weyn?/Et maintenant on va où?]. Roteiro: Rodney Al Haddid, Jihad Hojeily, Nadine Labaki e Sam Mounier, com a colaboração de Thomas Bidegain; Direção: Nadine Labaki; Produção: Les Films des Tournelles, Pathé, Les Films de Beyrouth, United Artistic Group, Prima TV, France 2 Cinéma. DVD Europa Filmes. França / Líbano / Egipto / Itália, 2011. 1 DVD (110 min.): color. 